\title{
Mobility needs, activity patterns and activity flexibility: How subjective and objective constraints influence mode choice
}

\author{
Thorhauge, Mikkel; Kassahun, Habtamu Tilahun; Cherchi, Elisabetta; Haustein, Sonja
}

Published in:

Transportation Research Part A: Policy and Practice

Link to article, DOI:

10.1016/j.tra.2020.06.016

Publication date:

2020

Document Version

Peer reviewed version

Link back to DTU Orbit

Citation (APA):

Thorhauge, M., Kassahun, H. T., Cherchi, E., \& Haustein, S. (2020). Mobility needs, activity patterns and activity flexibility: How subjective and objective constraints influence mode choice. Transportation Research Part A: Policy and Practice, 139, 255-272. https://doi.org/10.1016/j.tra.2020.06.016

\section{General rights}

Copyright and moral rights for the publications made accessible in the public portal are retained by the authors and/or other copyright owners and it is a condition of accessing publications that users recognise and abide by the legal requirements associated with these rights.

- Users may download and print one copy of any publication from the public portal for the purpose of private study or research.

- You may not further distribute the material or use it for any profit-making activity or commercial gain

- You may freely distribute the URL identifying the publication in the public portal 


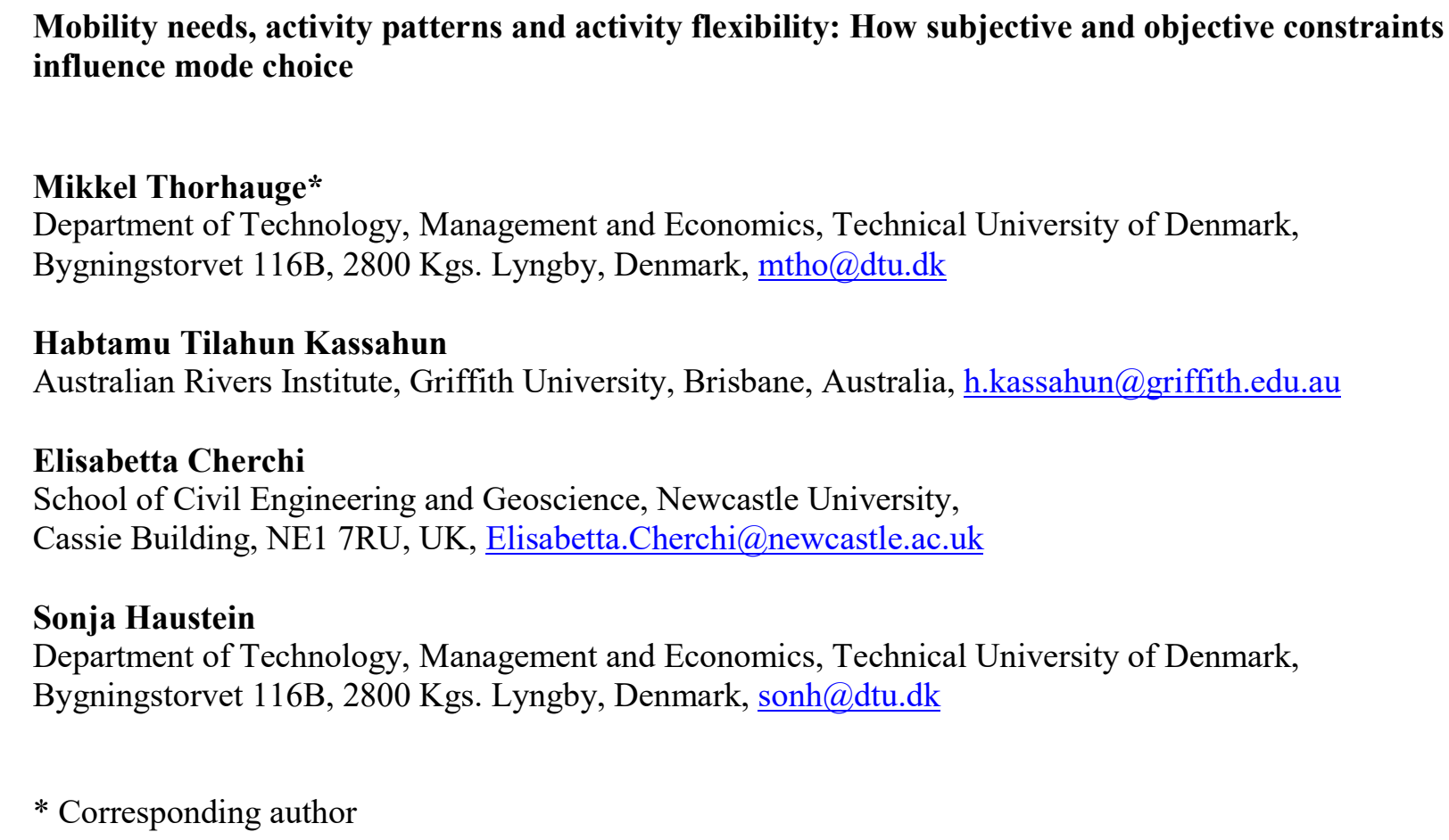

\section{Abstract}

Denmark is one of the world-leading countries in terms of bicycle infrastructure and has a relatively good public transport system. Yet, a large share of commuters in the Greater Copenhagen Area still uses the car on a regular or semi-regular basis, causing severe problems of congestion and pollution. This article seeks to understand to what extent individuals' perceived mobility necessities (PMN), activity pattern complexity, and temporal, spatial, social, or compulsory constraints in everyday activities inhibit switching from private motorized transport modes to more environmentally friendly modes. We formulate an Integrated Choice and Latent Variable model that accounts for PMN and activity patterns, complexity and constraints. To estimate the model, we used two datasets: the first dataset is the Danish National Transport Survey, which is a large dataset consisting of approximately 150,000 respondents; the second is a small(er) but highly detailed dataset, which contains relevant information regarding activity patterns, constraints and PMN. We found that the more complex the activity patterns are, the higher are both PMN and the probability of selecting car and bike, and this effect is even more evident when individuals are constrained by some activities. Consistently, individuals who perceive high mobility needs are more likely to select car and bike. The result that mobility needs and related constraints increase cycling conflicts with results found in low-cycling countries. Yet, it indicates that the bike can play a similar role as the car when the respective infrastructure is provided. Our results also indicate that structural improvements, such as flexible work and day-care times, day-care service close to the workplace, or escorting services for children are likely to lead to a substantial reduction in the use of the car. 
- Detailed information on perceived mobility needs as well as activity constraints (temporal, spatial, social, and compulsory) were collected

- Perceived Mobility Necessities (PMN) are positively associated with car and bike use

- Individuals with complex activity patterns and activity constraints are less likely to select public transport, and more likely to use car and bike

- PMN increase with the number of daily activities and constraints

- Commuters with high PMN are less likely to shift away from car to public transport as a result of a policy that involve the implementation of designated bus lanes

Keywords: Mode Choice, Perceived Mobility Necessities, Daily activity patterns, Flexibility constraints, 53 Integrated Choice and Latent Variable Model 


\section{Introduction}

56 Denmark - and Copenhagen in particular - is one of the world leading places in terms of bicycle infrastructure and demand (Haustein et al., 2019a; Pucher and Buehler, 2012). Yet, a large share of commuters in the Greater Copenhagen Area still uses the car on a regular or semi-regular basis (Vejdirektoratet, 2016), causing severe problems of congestion and pollution. It has been estimated that approximately 130,000 hours are wasted being stuck in traffic every day in the Greater Copenhagen Area, which equals 800-1100 million Euros per year (COWI, 2012; Municipalities, 2008). These effects are even more evident in other cities around the world, where the numbers of inhabitants and commuters are much higher than in Copenhagen, while bicycling is less common (or even non-existing) leading to even more severe transport problems.

In the last decades, city planners have looked at a variety of solutions to address this problem. Attempts have been made through improvements of alternative transport modes, such as public transport systems (e.g., the BRT-system "TransMilenio" in Bogota, Hidalgo et al., 2013) and bicycle infrastructure (e.g., Skov-Petersen et al., 2017). In addition, car-restrictive policies, such as road pricing (e.g., Börjesson et al., 2012) or parking management (e.g., Buehler et al., 2017) have been introduced in several cities. Besides these hard measures, soft measures, such as information provision and awareness campaigns have been used to achieve voluntary changes in mode choice (e.g., Bamberg, 2013; Cairns et al., 2008; Cherchi et al., 2017; Möser and Bamberg, 2008).

Despite this wide range of initiatives, cities around the world are still struggling with severe congestion problems (e.g., Becker et al., 2019) as many commuters are reluctant or unable to switch to alternative transport modes. Studies have shown that mode choice is one of the most in-elastic day-to-day travel decisions individuals make (Hendrickson and Planke, 1984; Hess et al., 2007). This makes it even more important and interesting to understand why individuals choose as they do in order to find the right leverage to promote a mode choice switch. While mode choice has been explained by a variety of factors and models, this paper focusses specifically on the effect of activity complexity and constraints from both the objective and subjective perspective.

\subsection{Travel mode choice and the role of activities and constraints}

The literature on factors influencing travel mode choice is vast (see a summary in Ortúzar and Willumsen, 2011). Of particular interest for this paper is research that has focused on activity participation and trip complexity and on subjective constraints and mobility needs.

Activity participation is an integral part of everyday life. Activities can be mandatory or discretionary (Yamamoto and Kitamura, 1999), performed alone or jointly with family and/or friends (Chandrasekharan and Goulias, 1999; Thorhauge et al., 2012; Yarlagadda and Srinivasan, 2008), and restricted or non-restricted in terms of time and space (Bowman and Ben-Akiva, 2000).

Furthermore, to increase scheduling efficiency, trip chaining is becoming more important and has gained more focus from researchers (Cirillo and Axhausen, 2002; McGuckin et al., 2005). Several studies have investigated mode choice decision seeking to understand how to promote and increase ridership of environmentally friendly modes instead of the car (e.g., Chakrabarti, 2017), and many studies focus on how trip chaining influence the choice of transport mode, in particular bicycle (Cao et al., 2008) and public transport (Vande Walle and Steenberghen, 2006). Xianyu (2013) studied "whether the behaviour of linking activities to the work trip is conditional on the commute mode choice or vice versa", and found the impact of activities on the mode choice to be the dominant relationship. Trip chaining is more likely to be undertaken using transport modes that are 
spatially and temporally flexible, easy to access, and multi-objective travel friendly (Wan and Candidate, 2011), which seems most likely to be private modes, while public transport seems less suitable (Dong et al., 2006). Ye et al. (2007) explored the relationship between commuters' mode choice and the complexity of their trip chains and found that driving was associated with (more) complex commute chains. However, some studies also find the reverse effect (Currie and Delbosc, 2011). Cherchi and Cirillo (2014) found that the type of activities had little influence on the mode choice over a six week period, instead the preferences for a specific mode was influenced by the amount of time allocated to activities. Furthermore, it has been found that morning and evening commute stops (i.e. intermediate activities) are more likely to be carried out by women, and the likelihood increases with age and income (Chu, 2003).

Subjective factors have often been operationalised in the theoretical framework of the Theory of Planned Behaviour (TPB, Ajzen, 1991; see e.g. Bamberg et al., 2007; Donald et al., 2014; Lanzini and Khan, 2017). Here, it has been shown that people's mode choice can be modelled by the intention to use a specific mode, while intention itself is determined by three factors: (1) the degree to which the use of the respective mode is positively or negatively valued (attitude), (2) the perceived social pressure to use the mode (subjective norm), and (3) the perceived ability to use it (perceived behavioural control). Perceived behavioural control (PBC) influences behaviour also directly. The higher the perceived restrictions, the less relevant is the intention and its antecedents.

Haustein and Hunecke (2007) extended the TPB by introducing the construct of perceived mobility necessities (PMN). Background for this addition was that the operationalisation of PBC mainly focuses on transportrelated constraints (e.g., trip distance, car/bike availability, transport infrastructure, see Bamberg, 2012), while constraints related to the personal living situation are only captured indirectly. PMN were introduced to directly account for the mobility-related consequences of the personal living circumstances (e.g., having children, a full-time job, complex daily routines) and turned out to improve the model fit when being added to a TPB model as a predictor for the use of alternative transport modes to the car. In-depth interviews additionally carried out in Haustein and Hunecke (2007) revealed that women with high PMN often had children and a job outside home, and they felt a high necessity to escort their children by car to several activities. They perceived it as impossible to switch from the car to public transport because of limited flexibility and long travel times. In addition, their (or their children's) typical destinations were often located less central. A study by Shirgaokar and Lanyi-Bennett (2019) also found that women's higher engagement in home-serving tasks (in addition to paid work) and related time constraints is associated to more time spent driving. Constraints and demands created by family and household responsibilities have also been identified as barriers of car use reduction in studies on cycling (e.g., Bonham and Wilson, 2012; Pooley et al., 2013).

While it has been shown that PMN are related to socio-demographic variables, like having children or a job, and to perceived time pressure, it so far remains unclear what exactly makes people perceive high mobility needs and to what extent this is related to the structure of their specific daily activities. Besides, studies that identified time restrictions and mobility needs as a barrier to increase cycling were conducted in low-cycling countries. In Copenhagen and other cycling cities, where the bike is perceived as an effective transport mode (Haustein et al., 2019a), it may have a similar function as the car, so that its use may increase with complexity of everyday life. 


\subsection{The present study}

This research is motived by the need to better understand how, and to what extent, mode choice decisions are influenced by our everyday activities and their temporal, spatial or social constraints and the perception of these constraints. More specifically, we have the following hypotheses:

(1) Commuters who have a more complex everyday life (indicated by the type of activities) are less likely to choose public transport, and more likely to select the car. Other than in low cycling countries, where cycling is hampered by family and household related demands (e.g. Pooley et al., 2013), we expect that a high number of activities in the cycling city of Copenhagen not only favours car use but also cycling.

(2) The effect of the activities on mode choice is even stronger, when activities are characterised by temporal, spatial, social and/or compulsory constraints.

(3) PMN are influenced both by the number of activities

(4) and the activities' constraints.

(5) Commuters with high PMN are more likely to choose individual transport modes (car and bike), and less likely to choose public transport.

To test these hypotheses, we use two rich data sources from Denmark. Section 2 reports a description of the datasets. We estimated an Integrated Choice and Latent Variable (ICLV) model, that consists of two components: a mode choice model, which is a function of the activity patterns, constraints and perceived mobility needs (as well as socio-demographic and level-of-service variables), and a latent variable model for the PMN, which is a function of both the complexity of the activity patterns and the constraints. Section 3 describes the model structure. We present the model results and provide a detail discussion in Section 4 and Section 5 .

\section{Data}

\subsection{Data sources}

In this paper, we used two data sources. The first is the Danish National Travel Survey, Transportvaneundersøgelsen (TU; Christiansen, 2018). This dataset has been collected ongoing since 2006 with about 1000 interviews per month (approx. $80 \%$ by telephone and $20 \%$ on the internet), and currently consists of 150,000 individuals between 10-84 years of age. The survey is administered by the Center for Transport Analytics of the Department of Technology, Management and Economics at the Technical University of Denmark.

TU collects a full trip diary of all trips and (out-of-home) activities during a $24 \mathrm{H}$ period (starting and ending 3:00 a.m.), and collects information about trip length, departure time, travel time, mode, purpose at destination as well as area codes ${ }^{1}$ at both ends of the trip. Furthermore, TU collects various background characteristics of the individual (socio-demographic-economic), the household (family members, location, and car ownership), the work place (location and parking facilities), as well as the transport possibilities (have a driver's license, holds a season pass, has a bike). More information about TU can be found in Christiansen and Warnecke (2018) and Christiansen and Skougaard (2015).

\footnotetext{
${ }^{1}$ Area codes are defined consistently with the zone system used in the Danish National Transport model.
} 
The second data source, Specialundersøgelsen (SU), is a more in-depth survey, that was collected for a project on departure time modelling of commuting trips (Thorhauge, 2015). Data was collected first in 2013 and later again in 2017 to a pool of new respondents. This survey contains the same information as the TU-data (and is consistent with TU in terms of data structure and variable codes) but collected additional information about activity and trip constraints, latent variables as well as a stated choice experiment specifically designed to capture departure time preferences (the latter part is not relevant for this specific study).

The SU-data was collected directly at the workplaces among employees at universities, public organizations and private companies located in Copenhagen. Thus, the sample was designed specifically to target individuals who commute to work in the city during the morning rush hours and arrive at work between 6-10 a.m. The workplaces were selected based on their location and the amount of and diversity among employees. The five workplaces selected hold more than 16,500 employees, and there were no restrictions on which of the employees could participate. It is common to select the workplaces strategically when interviewing based on the destination (see for example the Santiago panel as described in Yáñez et al., 2010). The survey was distributed through emails containing a link to the online-questionnaire. More than 10,000 questionnaire links were distributed and 923 interviews were filled in, resulting in a response rate of almost $10 \%$. More information on the data and data collection process can be found in Thorhauge et al. (Thorhauge et al., 2019, 2016).

In the following we will describe the parts unique to the SU-data, which are of relevance for this specific study. Firstly, a set of questions was defined to collect information about the flexibility of each trip reported in the trip diary and/or the activity tied to the specific trip. More specifically, following the typical literature in time geography (Hägerstrand, 1970) three types of constraints were considered: temporal, spatial and social constraints. Additionally, it was also considered whether the activity was compulsory or not. The four questions on constraints used in this specific study are presented in Table 1. More details on the trip chains and flexibility components can be found in Thorhauge et al. (2016).

\begin{tabular}{lll}
\hline Constraints & Questionnaire questions \\
\hline 1. & Spatial constraints: & Could you have carried out this activity at another location? (yes/no). \\
2. & Temporal constraints: & Were there any restrictions to how late you could have arrived? $\left(\mathrm{yes} / \mathrm{no}^{2}\right.$ ) \\
3. $\quad$ Social constraints: & Did you decide yourself when to depart? (yes/partly/no) \\
4. $\quad$ Compulsory constraints: & Could you have omitted this trip/activity? (yes/no) \\
\hline
\end{tabular}

Table 1: Measures of constraints.

Secondly, 24 indicator statements were designed to capture various latent constructs thought to be relevant for transport related decisions (especially departure time, but also more general latent constructs). Of particular relevance for this study are three items operationalising the latent construct of Perceived Mobility Necessities as defined by Haustein and Hunecke (2007). The indicators were assessed on a 5-point Likert scale (Likert, 1932) ranging from "totally disagree" (1), and to "totally agree" (5). The items are presented in Table 2.

\begin{tabular}{|c|c|c|c|}
\hline Indicators & Mean & Std. Dev. & Skewness \\
\hline 1. The organization of my everyday life requires a high level of mobility & 3.20 & 1.28 & -0.18 \\
\hline 2. I have to be mobile all the time to meet my obligations & 3.11 & 1.32 & -0.10 \\
\hline 3. My work requires a high level of mobility & 2.84 & 1.24 & 0.18 \\
\hline
\end{tabular}

Table 2: Indicators for the latent variable Perceived Mobility Necessities. Chronbach's alpha is 0.83 .

\footnotetext{
2 If they replied "yes", we also asked what the latest possible arrival time was.
} 


\subsection{Level of service data}

The datasets described above contain detailed information about (all) the trips individuals performed, such as mode, travel time, purpose, etc., but no information about non-chosen alternatives was available, which are necessary to estimate (mode) choice models.

In order to obtain Level-of-Service (LoS) for each respondent's non-chosen alternatives we relied on the Danish National Transport Model (Rich and Hansen, 2016). This is a 907-zone nationwide transport model consisting of 11 time periods and provides travel times, cost, and length among all combinations of OD-pairs for each mode and time period. Based on origin and destination of the trips reported by the respondents, we then joined the NTM-records with our data to obtain LoS-data for each trip in the sample. Time-of-day specific travel time (and length) is given directly from the NTM for each mode. For public transport, the Level-ofService components in the NTM consist of in-vehicle time (IVT), (walk) transfer time $(\operatorname{Tr} T)$ between e.g. a bus stop and a station platform, waiting time (WT), hidden waiting time (HWT), access-egress time ( $A c E g T)$ as well as the number of transfer (\#Tr). The travel time for bike and walk in the NTM is computed as a function of the network length between OD-pairs, and it is assumed independent of the time-of-day, because congestion is rarely a relevant factor for the travel time by bike and walk.

The cost for car users consists of two parts. First of all, based on the network length provided by NTM a cardriving cost is computed assuming $0.85 \mathrm{DKK} / \mathrm{km}^{3}$, which reflects gasoline prices. Secondly, based on the trip destination we also joined our data with information about parking prices for the zones in Copenhagen, which enabled us to compute parking cost for the duration of the stay in that zone (if applicable for that zone). For public transport costs, we used ticket prices from origin (home) to destination (work) of the commuting journey. Ticket prices are conditional on whether individuals hold a season pass or not. For individuals not holding a season pass, we specified ticket prices equal to the cost of a single ticket. For individuals holding a season pass we converted the monthly season pass cost into an average cost for each trip, by dividing the price of the monthly ticket by the number of days per month individuals commute to work. In our data we know how many days per month individuals worked from home, which was used to compute the number of single trips (both outbound and homebound) over the course of a month (assuming 20 working days per month on average), which ultimately allowed us to compute the average cost per trip. We verified that for all individuals the computed cost was lower than the corresponding cost for a single ticket. Bike and walk alternatives are assumed to have no cost.

Finally, the LoS from the NTM were also used for the chosen mode, instead of the travel time and length reported by the respondents. This was done for two reasons: First, for consistency among level-of-services for the different modes. And second, because the travel times reported in the questionnaire are often overestimated (due to round-off or political bias). By relying on the NTM for both the chosen and non-chosen alternatives we avoid both issues.

\subsection{Sample}

The final sample used in this research consists of morning commuters travelling in the Greater Copenhagen Region, see Figure 1, between 6:00-10:00 A.M. using one of the following 5 modes: walking, cycling, car as driver, car as passenger or public transport (transit). The reason why we focussed on commuting trips into Copenhagen is because it makes the mode choice decision highly relevant due to congestion, in contrast to rural areas, where congestion (and lack of "appealing" alternatives to the car) is typically not present. We note that, despite the fact that TU is nationwide, we focus on the Greater Copenhagen Area, which ensures

\footnotetext{
${ }^{3}$ Equivalent to $0.11 \mathrm{EUR} / \mathrm{km}$.
} 
geographical consistency with the SU dataset. The final sample consists of 10,784 individuals. Table 3a-c (in appendix) presents detailed descriptive statistics for the entire sample as well as grouped by dataset and mode. More specifically, it shows that 50.8 percent of the sample are women, while the average age is 37.7 (std. dev. $=15.3$ ), the average income is $361,600 \mathrm{DKK}$ (std. dev. $=289,200$ ), and the average commuting distance to work is $12.6 \mathrm{~km}($ std. dev. $=12.9)$. We also note that on average individuals carry out 3.6 activities per day. Furthermore, cyclists and car drivers have the highest number of daily activities ( 3.8 on average), followed by pedestrians and car passengers (on average 3.6 and 3.4 activities per day respectively), while public transport users are the group with the lowest number of daily activities ( 3.1 on average). We note a significant difference in the modes used between men and women, with men being more often car drivers, and women using more often other modes.

While TU-data are representative of the Danish (and hence Copenhagen) population, the same cannot be claimed for the SU-data (e.g. car drivers were deliberately oversampled); however, SU-data it is not significantly different from TU-data in some key areas (especially) relevant for this study, such as average commuting time and distance as well as proximity to public transport, number of cars in households, household size, working hours and income.

Finally, we defined the availability conditions for each mode as specified below:

$$
\begin{aligned}
\text { Walking } & =\left\{\begin{array}{l}
\text { Walking is the choosen (observed) mode of transport } \\
\text { Work within } 5 \mathrm{~km} \text { from home }
\end{array}\right. \\
\text { Cycling } & =\left\{\begin{array}{l}
\text { Cycling is the choosen (observed) mode of transport } \\
\text { or } \quad \text { Respondent has a bike AND work within } 25 \mathrm{~km} \text { from home }
\end{array}\right.
\end{aligned}
$$

Car as driver $=\left\{\begin{array}{l}\text { Car as driver is the choosen (observed) mode of transport } \\ \text { or } \quad \text { Respondent has a drivers license AND car is accessible }\end{array}\right.$

Car as passenger $=\left\{\begin{array}{l}\text { Car passenger is the choosen (observed) mode of transport } \\ \text { or } \quad \text { Min } 1 \text { other adult in HH has a driv. license AND car is accesible }\end{array}\right.$

Public transport $= \begin{cases} & \text { Public transport is the choosen (observed) mode of transport } \\ \text { or } & \text { Respondent has a public transport pass } \\ \text { or } & \text { Station within } 10 \mathrm{~km} \text { from home }\end{cases}$

Regarding the availability of car passengers, this information is not included in our dataset, so we cannot know exactly when this option is available (e.g. individuals could catch a ride with colleagues). It is our general understanding that catching a ride with a colleague is not very common in Denmark (possibly due to a fairly good coherent public transport system and a strong cycling culture providing good alternatives). We analysed the Danish National Transport Survey and found that less than $10 \%$ of commuting trips as car passengers were undertaken with colleagues, while more than $90 \%$ of all car passenger trips were done with a household member. Based on this, we decided to define the availability for the car passenger alternative as outlined above, rather than just setting the car passenger option to be available for everybody. Table 4 shows the distribution among modes for the two datasets, as well as how often each mode is available. We note an equal share for cyclists and car passengers. SU-data has a lower share of public transport usage and walking, while a higher share of car drivers. Table 5 shows the mean and standard deviation for the Level-of Service attributes among

\footnotetext{
${ }^{4}$ car is assumed accessible if the household has at least one car or is a member of car sharing
} 
278 available modes. Overall, the numbers look as expected, but we note a large standard deviation in car costs. 279 This is because some respondents have to pay a high cost for (street) parking (dependent on the area) while 280 others do not.

\begin{tabular}{|c|c|c|c|c|c|c|c|c|c|}
\hline & \multicolumn{3}{|c|}{ TU-data } & \multicolumn{3}{|c|}{ SU-data } & \multicolumn{3}{|c|}{ Total } \\
\hline & Chosen & [\%] & Available & Chosen & [\%] & Available & Chosen & [\%] & Available \\
\hline Walking & 676 & {$[6.6 \%]$} & 4,509 & 12 & {$[2.1 \%]$} & 174 & 688 & [6.4\%] & 4,683 \\
\hline Cycling & 3,426 & [33.5\%] & 7,723 & 198 & [35.0\%] & 444 & 3,624 & [33.6\%] & 8,167 \\
\hline Car as driver & 3,523 & [34.5\%] & 6,091 & 289 & [51.2\%] & 451 & 3,812 & [35.3\%] & 6,542 \\
\hline Car as passenger & 418 & [4.1\%] & 6,710 & 13 & {$[2.3 \%]$} & 377 & 431 & {$[4.0 \%]$} & 7,087 \\
\hline Public transport & 2,176 & [21.3\%] & 10,210 & 53 & [9.4\%] & 565 & 2,229 & [20.7\%] & 10,775 \\
\hline Total & 10,219 & [100.0\%] & & 565 & [100.0\%] & & 10,784 & [100.0\%] & \\
\hline
\end{tabular}

\begin{tabular}{lccccc}
\hline Mode & Walk & Bike & Car Driver & Car Passenger & Public Transport \\
\cline { 2 - 5 } Availability & $\mathbf{N}=\mathbf{4 6 8 3}$ & $\mathbf{N = 8 1 6 7}$ & $\mathbf{N}=\mathbf{6 5 4 2}$ & $\mathbf{N = 7 0 8 7}$ & $\mathbf{N}=\mathbf{1 0 7 7 5}$ \\
\hline Travel Cost [DKK] & & & $44.65(63.22)$ & $38.53(60.00)$ & $17.63(14.32)$ \\
Travel Time [min] & $26.65(8.58)$ & $23.46(13.92)$ & $22.12(13.32)$ & $19.24(13.97)$ & $16.91(14.25)$ \\
Waiting Time [min] & & & & $0.73(1.42)$ \\
Access/Egress Time [min] & & & & $15.9(7.94)$ \\
Hidden Waiting Time (headway) [min] & & & & $5.77(5.38)$ \\
Number of changes & & & & $0.41(0.57)$ \\
\hline
\end{tabular}

Table 5: Mean and std. dev. of Level-of-Service attributes for all available modes.

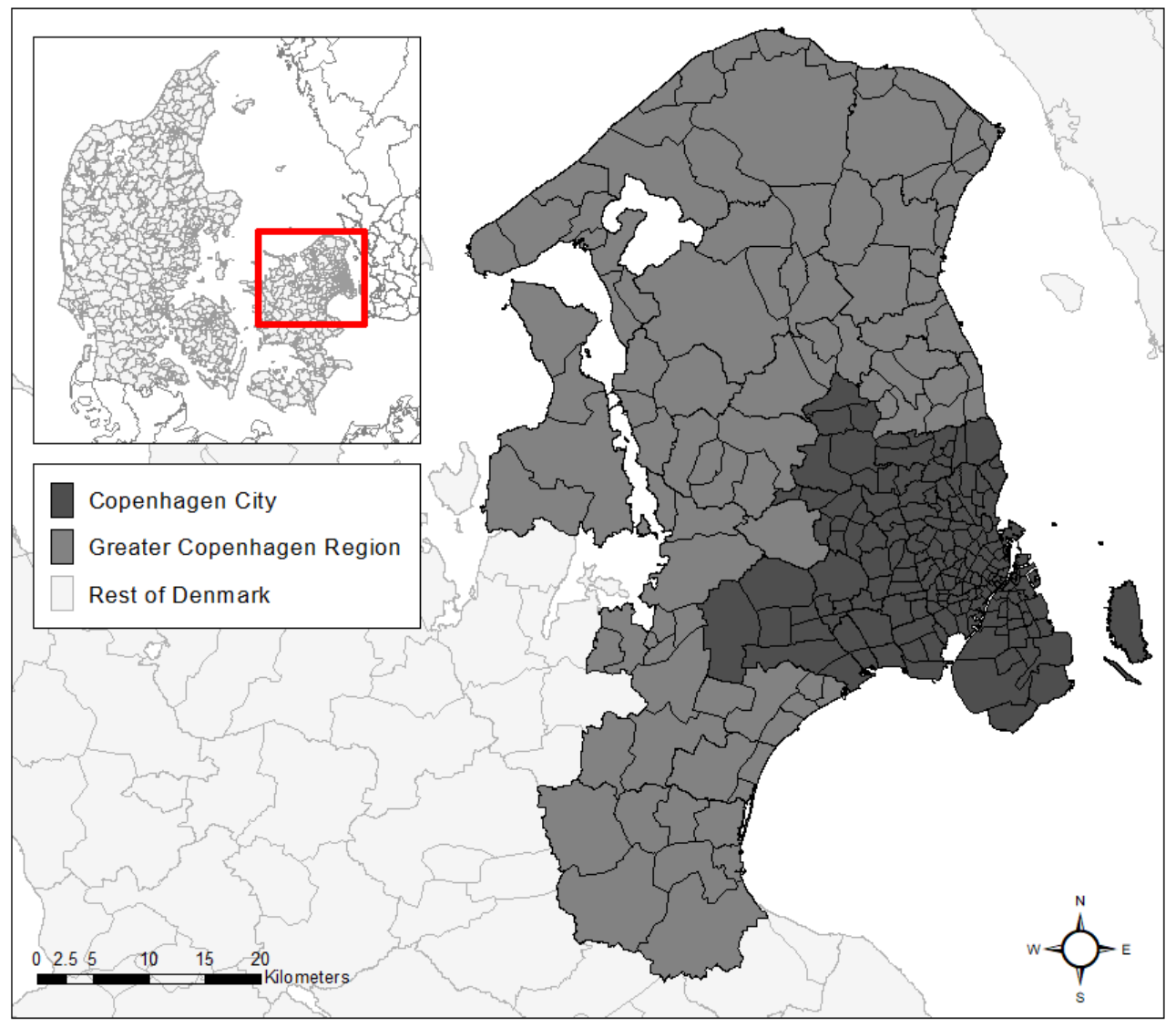

Figure 1: The study area was defined as the Greater Copenhagen Region. Only commuting trips with a final destination in the City of Copenhagen (dark grey area) were considered. 


\section{Mathematical model}

This section describes the modelling framework and specifies the mathematical formulation. The purpose of the model is to explicitly account for mobility needs, activities and constraints. We operationalise perceived mobility necessities (PMN) as a latent variable, following the traditional hybrid choice model framework (Walker, 2001; Walker and Ben-Akiva, 2002), which consists of a choice model and a latent variable model. The Integrated Choice and Latent Variable (ICLV) model is estimated simultaneously across two datasets described in Section 2 (i.e. TU and SU data) and is depicted in Figure 2. This allows us to take advantages of the strengths of each dataset. Utilizing TU-data enables estimating more robust core parameters, such as Levelof-Service (LOS) attributes, socio-demographics, and activity patterns, as wells as the alternative specific constants (ASC), while the SU enables estimating very detailed parameters regarding the latent variable PMN and activity constraints not possible with TU. As commonly done when estimating across two (or more) data sources, we append one dataset to the other, and account for the potential difference in scale by estimating a scale parameter.

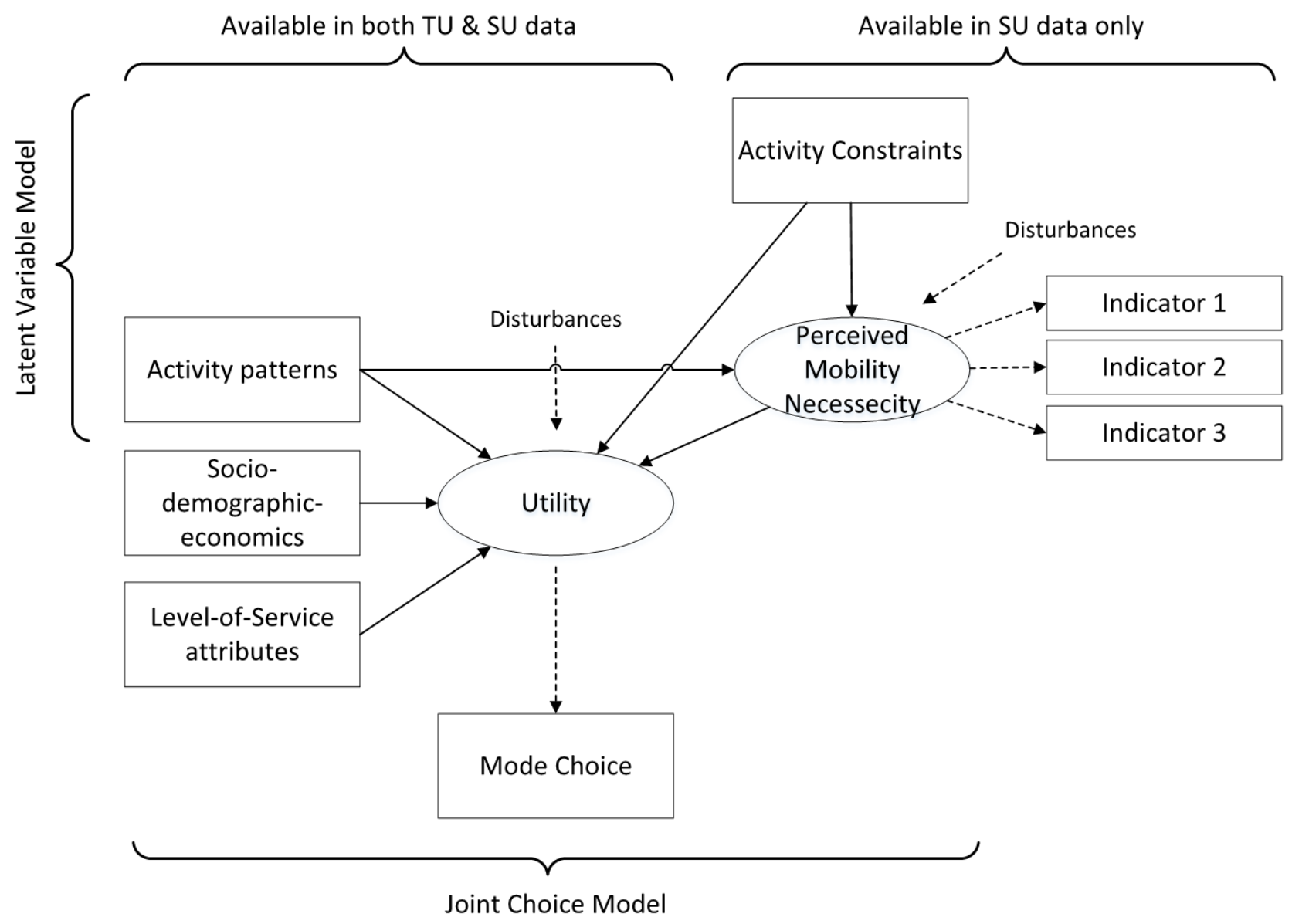

Figure 2: Overview of the model framework for the Integrated Choice and Latent Variable model.

We hypothesize that PMN is influenced by two components: a measure of the complexity of the activity patterns (such as number of activities, distance travelled, etc.), and a measure of the level of individuals constraints. We expect that PMN will increase when the complexity (i.e. number of activities or distance travelled) of the activity pattern increases. Similar, we expect PMN to increase when the (temporal, spatial, spatial, compulsory) constraints level increases, since trips with a low constraint level (i.e. highly flexible) can 
easier be re-scheduled, re-organized, re-planned or even cancelled and thus have a less "strict" influence on the perceived mobility necessities.

In turn, beside the common Level-of-Service attributes and individuals socio-demographic characteristics, we expect mode choice (for morning commute trips) to be influenced by activity patterns, constraints level and perceived mobility necessities. As highlighted in the introduction, we hypothesise that individuals with high perceived mobility necessities as well as many (different) types of activities performed in various times during the day will be more likely to select individual modes such as the car and the bike, that allow a higher flexibility, while individuals with simple activity patterns and highly flexible activities will be more likely to use public transport.

\subsection{Activity patterns and constraints}

As discussed in the literature review, the number of activities performed and the extent to which these are constrained, play a key role in the chosen transport mode. In order to capture this effect we use two aggregate measures. To capture the activity complexity we utilise the Shannon's entropy measure, the same as used in Thorhauge et al. (2016). Shannon's entropy measures the dispersion of activities (McBride et al., 2019, 2020; Scheiner, 2014) and it is defined as:

$$
H=-\sum_{t=1}^{T} p_{t} \ln \left(p_{t}\right)
$$

where $p_{t}$ is the percentage of activities performed in each trip chain $t . \mathrm{H}>0$ means that activities are scattered across multiple trip chains, while $\mathrm{H}=0$ means that all activities are performed in a single trip chain. It is expected that individuals with scattered the activities, i.e. performed in different trip chains, are more likely to prefer and select individual modes, such as bike and car, in order to ease chained trips.

The second aggregate measure is for the individuals' level of constraints. All information about activity constraints (presented in Table 1) were recoded so that all have the same direction (i.e. 1 indicates a constraint in dimension $c$, while 0 indicates flexibility in dimension $c$ ):

$$
\gamma_{c}=\left\{\begin{array}{l}
\text { 1: Constraint in dimension } c \\
0: \text { Flexible in dimension } c
\end{array}\right.
$$

A constraint-score is then computed to obtain an overall aggregate constraint level:

$$
\Gamma=\sum_{c=1}^{C} \gamma_{c} \mid \gamma_{c}=\{\text { Temporal, Spatial, Social, Compulsory activity constraints }\}
$$

We used the constraint-score as an explanatory variable for both perceived mobility necessities and mode choice utility specification as depicted on Figure 2. 


\subsection{Perceived Mobility Necessities (PMN)}

Perceived mobility necessities (PMN) is modelled as a latent variable. The structural model (2) and the measurement model (3), which the latent variable model, are specified as follows:

$$
P M N_{n}=\alpha+\lambda_{X} \cdot \boldsymbol{X}_{n}+\omega_{n}
$$

Where

- $\quad P M N_{n}$ is the latent (unobservable) variable for individual $n$.

- $\quad \boldsymbol{X}_{\boldsymbol{n}}$ is the vector of explanatory observed covariates including the constraint score and number of activities while $\lambda_{X}$ is the corresponding vector of unknown coefficients.

- $\quad \alpha$ is the constant in the structural equation for the latent variable.

- $\omega_{n}$ is a normally distributed error term with zero mean and variance $\sigma_{\omega}$.

The latent variable is specified using the set of $K=3$ indicators collected specifically for this purpose (see Table 2). The measurement equation for indicator $k$ and individual $n$ is defined according to the following expression:

$$
I_{n k}=\delta_{k}+\theta_{k} \cdot P M N_{n}+v_{n k}
$$

Where

- $\quad I_{n k}$ is the indicator $k$ of the latent variable $P M N$ for individual $n$.

- $\quad \theta_{k}$ is the coefficient associated with the latent variable $P M N$ for the indicator $k$.

- $\quad \delta_{k}$ is the constant in the measurement equation for the indicator $k$.

- $\quad v_{n k}$ is a normally distributed error term with zero mean and variance $\sigma_{v}$.

\subsection{Mode choice utility specification}

The choice model includes 5 alternatives: walking, cycling, car as driver, car as passenger and public transport, where "car" stands for individual motorized modes. The systematic utility functions for the two dataset (SU and TU) are mostly identical, with the exception that the utility function for the SU-data also accounts for the data-specific elements of activity constraints and the latent perceived mobility necessities (PMN) that were collected (only) in the SU dataset. The systematic utility $\left(V_{i n}\right)$ that is common for both dataset is specified as follows:

$$
V_{i n}=A S C_{i}+\boldsymbol{\beta}_{i}^{L o S} \cdot \operatorname{LoS}_{i n}+\beta_{i}^{E n t} \cdot E n t_{n}+\boldsymbol{\beta}_{i}^{A c t} \cdot \boldsymbol{A c t}_{\boldsymbol{n}}+\boldsymbol{\beta}_{\boldsymbol{i}}^{\boldsymbol{S}} \cdot \boldsymbol{S}_{\boldsymbol{n}}
$$

\footnotetext{
Where

- $\quad A S C_{i}$ is the alternative specific constant for alternative $i$. The car alternative is defined as reference.

- $\quad \boldsymbol{L o S}_{\boldsymbol{i n}}$ is a vector of Level-of-Service characteristics (such as travel time and cost) for each mode $i$ and individual $n$, while $\boldsymbol{\beta}_{\boldsymbol{i}}^{\boldsymbol{L} \boldsymbol{S}}$ is a vector of corresponding parameters to be estimated.

- $E n t_{n}$ is the aggregate measure of activity complexity (i.e. the Shannon's Entropy) for individual $n$, while $\beta_{i}^{E n t}$ is the corresponding parameter to be estimated.

- $\boldsymbol{A c t}_{\boldsymbol{n}}$ is a vector single activity dummies for individual $n$, while $\boldsymbol{\beta}_{\boldsymbol{i}}^{\boldsymbol{A} \boldsymbol{c t}}$ is a corresponding vector of parameters to be estimated.

- $\quad \boldsymbol{S}_{\boldsymbol{n}}$ is a vector of socio-demographic characteristics for individual $n$, while $\boldsymbol{\beta}_{\boldsymbol{i}}^{\boldsymbol{S}}$ is a corresponding vectors of parameters to be estimated.
}

Note that we decided to include the costs in the car passenger alternative as well. We did this because the vast majority of car passenger trips are done with household members as explained in Section 2.3, thus the cost is considered a joint household expense regardless of who is behind the wheel (In Denmark most households 
make a joint decision on car ownership because of the high taxation, so expenses are most often assigned to the household budget). The overall utility specification is defined as:

$$
\begin{gathered}
\widetilde{U}_{i n}^{S U}=\tilde{V}_{i n}^{S U}+\zeta \cdot\left(\varepsilon_{i n}^{S U}\right) \\
\widetilde{U}_{i n}^{T U}=\tilde{V}_{i n}^{T U}+\varepsilon_{i n}^{T U} \\
\tilde{V}_{i n}^{S U}=\zeta \cdot\left(V_{i n}^{S U}+\beta_{i}^{\Gamma} \cdot \Gamma_{n}^{S U}+\beta_{i}^{P M N} \cdot P M N_{n}^{S U}+\eta_{i} \cdot \mu_{i n}^{S U}\right) \\
\tilde{V}_{i n}^{T U}=V_{i n}^{T U}+\eta_{i} \cdot \mu_{i n}^{T U}
\end{gathered}
$$

Where:

- $\quad V_{i n}^{S U}$ and $V_{i n}^{T U}$ are defined as in equation (4)

- $\quad \Gamma_{n}^{S U}$ is the constraint score for individual $n$, and $\beta_{i}^{\Gamma}$ is the corresponding parameter to be estimated for alternative $i$.

- $\quad$ PMN is the latent Perceived Mobility Necessities for individual $n$, and $\beta_{i}^{P M N}$ is the corresponding parameter to be estimated for alternative $i$.

- $\quad \mu_{i n}^{S U}$ and $\mu_{i n}^{T U}$ are error components to account for uncaptured correlation between the two car alternatives, as well as random heterogeneity in the preferences for of the alternatives, while $\eta_{i}$ are the associated coefficient to be estimated.

- $\quad \varepsilon_{i n}^{S U}$ and $\varepsilon_{i n}^{T U}$ are the typical independent and identically distributed (i.i.d.) Extreme Value (EV) type 1 error terms.

- $\quad \zeta$ is a scale-parameter, to capture the potential difference in scale between the two data sources.

\subsection{Model Estimation}

Given the specifications of the utility functions described above, the conditional probability of individual $n$ choosing mode $i$ is given by:

$$
C P_{i n}^{d}=\frac{\exp \left(\tilde{V}_{i n}^{d}\right)}{\sum_{j=C_{n}^{d}} \exp \left(\tilde{V}_{j n}^{d}\right)} \quad \forall i, j \in C_{n}^{d} ; d=\{S U, T U\}
$$

The latent variable is only know to its distribution. Let $\Phi$ be the standard normal distribution function. Assuming independence among the LV (for simplicity), the distribution of the latent variable and the indicators are:

$$
\begin{gathered}
f_{P M N_{n}}=\frac{1}{\sigma_{\omega}} \Phi\left(\frac{P M N_{n}-\left(\alpha+\lambda_{\boldsymbol{X}} \cdot \boldsymbol{X}_{\boldsymbol{n}}\right)}{\sigma_{\omega}}\right) \\
f_{I_{n k}}(\omega)=\frac{1}{\sigma_{v_{k}}} \Phi\left(\frac{I_{n k}-\left(\delta_{k}+\theta_{k} \cdot P M N_{n}(\omega)\right)}{\sigma_{v_{k}}}\right) \quad \forall k \in K
\end{gathered}
$$

For the purpose of theoretical identification, we defined $\delta_{l}=0$ and $\theta_{l}=1$. 
The unconditional joint probability is the integral of the conditional probability over the distribution of $\omega_{q m}$ and $\mu_{j n}$. For the SU observations takes the expression:

$$
P_{i n}^{S U}=\int_{\omega}\left(\int_{\mu} C P_{i n}^{S U}\left(\mu_{i n}^{S U}, \omega_{n}\right) f(\mu) d \mu\right) f_{P M N_{n}}(\omega) \prod_{k=1}^{K} f_{I_{n k}}(\omega) f(\omega) d \omega
$$

For the TU observations takes the expression:

$$
P_{i n}^{T U}=\int_{\mu} C P_{i n}^{T U}\left(\mu_{i n}^{T U}\right) f(\mu) d \mu
$$

Let $y_{\text {in }}$ be a matrix of individual choice indicators:

$$
y_{i n}=\left\{\begin{array}{lc}
1 & \text { if individuals } n \text { selects alternative } i \\
0 & \text { otherwise }
\end{array}\right.
$$

The log-likelihood function then is given by the logarithm of the product of the unconditional probabilities $P_{\text {in }}$ :

$$
L L=\sum_{n} \sum_{i} y_{i n} \ln \left(P_{i n}^{d}\right) \quad d=\{S U, T U\}
$$

\section{Results}

\subsection{Model estimation}

This section presents the modelling results. All model estimations were done using PythonBiogeme 2.5 (Bierlaire, 2016). We estimated an integrated choice and latent variable (ICLV) model jointly across two RPdatasets containing a total of 10,784 observations (one observation per individual). The model contains 72 parameters in total for both the choice and latent variable components and was estimated using 10,000 draws. The final log-likelihood is $-10,055.021$, while AIC is 20,260.041 and BIC is 20,806.478. The final parameters estimated for the choice model are presented in Table 7, while the parameters estimated for the latent variable model are presented in Table 6.

As described in the modelling section, our mode choice model includes several explanatory variables, including activity complexity, constraints and the latent variable Perceived Mobility Necessities (PMN), other than alternative specific Level-of-Service attributes and individuals' background characteristics. Overall, we note that all parameters estimated for the level-of-service attributes are negative and significant (at least) at 95\% confidence level. We tested for income effects, but did not find them to be significant. To account for cost-damping effects, we applied a Box-Cox transformation for the travel cost and found the associated BoxCox-parameter to be significantly different from a linear assumption. For completeness, we also tested for nonlinear effects for the time components but did not find any cost-damping effects to be significant. The estimated 
average value of (in-vehicle) time (VOT) is 127.76, 104.74, and 44.17 DKK/hour for car drivers, car passengers, and public transport users, respectively. For comparison, the average VOT in a Danish context is found to be $121 \mathrm{DKK} /$ hour while being $93 \mathrm{DKK} /$ hour for the commuter segment (Fosgerau et al., 2007; Modelcenter, 2019). With respect to gender preferences, as expected, males are more likely to use the car (as driver), while females are more likely to use all other modes.

In line with Hypothesis 1, we included various dummies, to reflect if individuals engaged in certain activities during different periods of the day. We found that all parameters associated to these dummies (except the parameter for escorting activities performed in the morning by car) are positive, indicating that if individuals are engaging in escort, errand and/or leisure activities either during home-work commute, work-home commute and/or in the evening after returning back home from work, then they are more likely to use other modes than public transport. We believe this is due to the nature of timetable-based transport modes since every new activity involves access/egress trips as well as waiting time at every stop, making it a slow and inefficient way to facilitate complex activity patterns. Furthermore, we found that the entropy measure is positive and significant for the bike and car driver alternatives, indicating that the more activities are dispersed across multiple trip chains the more likely individuals are to use these two modes. This is also in line with Hypothesis 1, i.e. individuals with (more) complex activity patterns are more likely to use individual modes, such as car and bike.

In addition to that, we found that individuals who are constrained in their activities during the morning commute are less likely to use public transport (and thereby more likely to use individual modes), which confirms Hypothesis 2. Furthermore, we found that individuals with high(er) degree of PMN favour individual modes of transportation, such as car and bike, as these makes it relatively easier to get around and engage in various activities. This confirms Hypothesis 3.

The latent variable PMN is influenced by two (observable) components: the number of daily activities performed by the individuals, and a constraint-score that captures how constrained individuals are during the commute trip from home to work. We found that PMN increases as both the number of activities and the constraint-level increase, which confirms Hypotheses 4 and 5. The fact that PMN increases with individuals' constraint-level is reasonable because inflexible activities cannot be rescheduled, changed and/or cancelled, thus the (perceived) need for mobility is higher, oppose to flexible activities, which can be altered or cancelled, thereby making the (perceived) need for mobility less strict. In line with the existing literature, we also tested various socio-demographics (in particular related to the presence of children and the need of escorting them to/from activities) as explanatory variables for PMN, as well as including the total distance travelled in order to represent a spatial element of their activity pattern, but found none of these effects to be significant when also including the number of activities and constraints as explanatory variables. Since PMN has a positive impact on the utility for car drivers and cyclists, it means that individuals who have many daily activities and/or have a high level of constraints are more likely to select car or bike to address their needs and engage in activities. This is consistent and in line with direct effects confirmed for Hypothesis 1 and 2 above. 


\begin{tabular}{lrr}
\hline & Value & \multicolumn{1}{c}{ t-test } \\
\hline Structural Equation & & \\
\hline Intercept & 2.690 & 14.920 \\
Number of daily activities & 0.078 & 2.280 \\
Constraint-score & 0.103 & 1.730 \\
Sigma & 1.040 & 22.930 \\
\hline Measurement equations & & \\
\hline Indicator 1 & & \\
$\quad$ Std. Dev. & 0.722 & 13.680 \\
Indicator 2 & & \\
Intercept & -0.100 & -0.490 \\
LV coeff. & 1.000 & 17.000 \\
Std. Dev. & 0.794 & 15.590 \\
Indicator 3 & & \\
Intercept & 0.089 & 0.520 \\
LV coeff. & 0.859 & 15.350 \\
Std. Dev. & 0.839 & 19.340 \\
\hline
\end{tabular}

477 Table 6: parameter estimates for Latent variable model for Perceived Mobility Necessities (PMN). Parameters in italic:

$478 \mathrm{P}<0.05$. The constraint score is computed as a sum of the following four constraints variables, which represents

479 temporal, spatial, social, and compulsory constraints: 1) Did you have any constraints in terms of how late you could 480 arrive? 2) Could you have performed this activity at another location? 3) Did you decide yourself when to depart? 4) 481 Could you have omitted this activity? 


\begin{tabular}{|c|c|c|c|c|c|c|c|c|c|c|c|c|}
\hline & \multicolumn{2}{|c|}{ Walk } & \multicolumn{2}{|c|}{ Bike } & \multicolumn{2}{|c|}{ Car driver } & \multicolumn{2}{|c|}{ Car passengers } & \multicolumn{2}{|c|}{$\begin{array}{c}\text { Public } \\
\text { Transportation }\end{array}$} & \multicolumn{2}{|c|}{ Multiple modes } \\
\hline & Value & t-test & Value & t-test & Value & t-test & Value & t-test & Value & t-test & Value & t-test \\
\hline \multicolumn{13}{|l|}{ Level-of-Service, ASC, scale, and error components } \\
\hline ASC & 6.590 & 8.850 & 2.340 & 3.770 & & & -4.160 & -3.680 & -0.076 & -0.100 & & \\
\hline Travel Time [1/min] & -0.366 & -15.110 & -0.280 & -12.920 & -0.064 & -5.920 & -0.048 & -3.400 & -0.046 & -3.880 & & \\
\hline Waiting Time [1/min] & & & & & & & & & -0.182 & -2.710 & & \\
\hline Access/Egress Time [1/min] & & & & & & & & & -0.051 & -3.640 & & \\
\hline Hidden Waiting Time (Headway) [1/min] & & & & & & & & & -0.100 & -4.760 & & \\
\hline Number of changes & & & & & & & & & -0.395 & -2.410 & & \\
\hline Travel Cost for car driver, car passenger and public transport [1/DKK] & & & & & & & & & & & -0.833 & -5.800 \\
\hline BoxCox parameter for Travel Cost (T-test against 1 ) & & & & & & & & & & & 0.092 & -28.854 \\
\hline Scale between TU \& SU data (T-test against 1) & & & & & & & & & & & 0.937 & -0.327 \\
\hline Error Component - Std. Err of ASC & & & 2.040 & 7.020 & & & 3.290 & 4.190 & & & & \\
\hline Error Component - car driver \& car passenger & & & & & & & & & & & 2.720 & 4.490 \\
\hline \multicolumn{13}{|l|}{ Socio-demographics } \\
\hline Household has 1 car & & & & & -1.270 & -2.240 & & & & & & \\
\hline Household has $2+$ cars & & & & & 1.260 & 2.150 & & & & & & \\
\hline Parking available at work & & & & & 1.370 & 5.050 & & & & & & \\
\hline Parking free at work & & & & & 1.040 & 4.610 & & & & & & \\
\hline Age $<30$ & 0.403 & 1.970 & & & & & 1.090 & 2.440 & 0.433 & 3.110 & & \\
\hline Age $>=50$ & & & & & & & 0.702 & 2.300 & & & & \\
\hline Male & -0.659 & -3.210 & -0.457 & -2.520 & & & -2.300 & -5.120 & -0.841 & -4.620 & & \\
\hline Education, University degree & 0.680 & 2.700 & 1.700 & 7.400 & & & & & 0.860 & 4.060 & & \\
\hline Education, Elementary school & & & & & & & 0.583 & 1.440 & 0.781 & 3.980 & & \\
\hline Education, High school & & & 0.878 & 4.010 & & & & & 1.020 & 4.410 & & \\
\hline Work hours per week $=37 \mathrm{H}$ & & & 0.725 & 4.330 & & & & & 0.487 & 3.270 & & \\
\hline Work hours per week $<37 \mathrm{H}$ & 0.721 & 2.530 & 1.230 & 4.610 & & & & & 1.300 & 4.930 & & \\
\hline \multicolumn{13}{|l|}{ Activities and constraints } \\
\hline Entropy & & & 0.587 & 2.49 & 1.04 & 3.73 & & & & & & \\
\hline Has Errand activity - Home-Work & 4.300 & 2.550 & 1.600 & 2.220 & & & 2.120 & 2.450 & & & & \\
\hline Has Errand activity - Work-Home & & & & & 1.150 & 4.590 & 1.360 & 3.470 & & & & \\
\hline Has Errand activity - After-Work & & & 0.534 & 3.500 & & & & & & & & \\
\hline Has Escort activity - Home-Work & 4.110 & 6.340 & 0.714 & 2.300 & -0.722 & -2.500 & & & & & & \\
\hline Has Escort activity - Work-Home & & & & & 0.853 & 3.410 & 0.870 & 2.350 & & & & \\
\hline \multicolumn{13}{|l|}{ Has Escort activity - After-Work } \\
\hline Has Leisure activity - Home-Work & 5.110 & 5.160 & & & & & & & & & & \\
\hline Has Leisure activity - Work-Home & & & 0.587 & 3.930 & 0.822 & 3.240 & & & & & & \\
\hline Has Leisure activity - After-Work & 0.323 & 1.980 & 0.543 & 4.140 & & & & & & & & \\
\hline \multicolumn{13}{|l|}{ Only estimated using SU-data (information not available in TU) } \\
\hline LV PMN & & & 0.269 & 1.910 & 0.289 & 2.010 & & & & & & \\
\hline Constraint-score & & & & & & & & & -0.356 & -2.270 & & \\
\hline
\end{tabular}

484 Table 7: Mode choice model parameter estimates. Parameters in italic: $\mathrm{P}<0.05$. The constraint score is computed as a sum of the following four constraints variables,

485 which represents temporal, spatial, social, and compulsory constraints: 1) Did you have any constraints in terms of how late you could arrive? 2) Could you have

486 performed this activity at another location? 3) Did you decide yourself when to depart? 4) Could you have omitted this activity? 


\subsection{Policy scenario: forecasting implication of a Toll Ring}

The estimated mode choice model allows us to forecast the effect of policy scenarios. In line with the increased congestion and higher environmental awareness, many cities are looking into raising the level of service of their transit system. One effective solution is to implement designated bus lanes or signal prioritization, to avoid having the busses being stuck in traffic. Prioritizing busses often results in increased travel times for car commuters due to either less capacity (e.g. by converting a car lane into a designated bus lane) or shorter green light cycles. To mimic such a policy scenario, in our forecasting simulation we assumed that the travel time for bus decreased by $20 \%$ while the travel time for cars increased by $20 \%$. Furthermore, we assumed that the time-of-day and the destination of the trips remain constant, since modelling such changes would require a full transport model, which is beyond the scope of this paper. This assumption is of course not realistic, but nevertheless useful for the purpose of illustrating the behavioural insights our model provides.

In this forecast, we only utilize the individuals from the SU-data, since we are mainly interested in understanding the effect of how (complexity of) activities, constraints and (perceived) mobility influence the mode choice, which (for the latter two) are only available in this dataset. Figure 3 presents the substitution patterns as a result of implementing a policy scenario in which public transport is prioritized. The horizontal line shows the substitution pattern for the entire SU-data sample, and we note that the car alternatives loses market shares, while the public transport and bike alternatives gain market shares. Furthermore, we segmented the sample based on their level of Perceived Mobility Necessities (PMN) into three segments based on the tertiles. Thus, the first group consists of the bottom third of individuals with the lowest PMN, while the second group consists of the middle third of individuals with medium PMN (centred around the median), and the third and last group consists of the top third of individuals with the highest PMN. We see a distinct difference in how the three segments react to the implementation of such a policy scenario. Interestingly, among individuals who shifted away from car we note that in the segment with the lowest PMN, approx. $90 \%$ shifted to public transport, while only $10 \%$ shifted to bike. However, in the segment with the highest PMN, approx. $60 \%$ shifted to public transport, while $40 \%$ shifted to bike. This is in line with our hypothesis that individuals with high mobility needs prefer individual modes and avoid public transport. Thus, if car users are to change transport mode, those with more complex activity patterns and higher mobility needs are more likely to shift to bike (as compared to other groups). 


\section{Substitution patterns}

$3.0 \%$

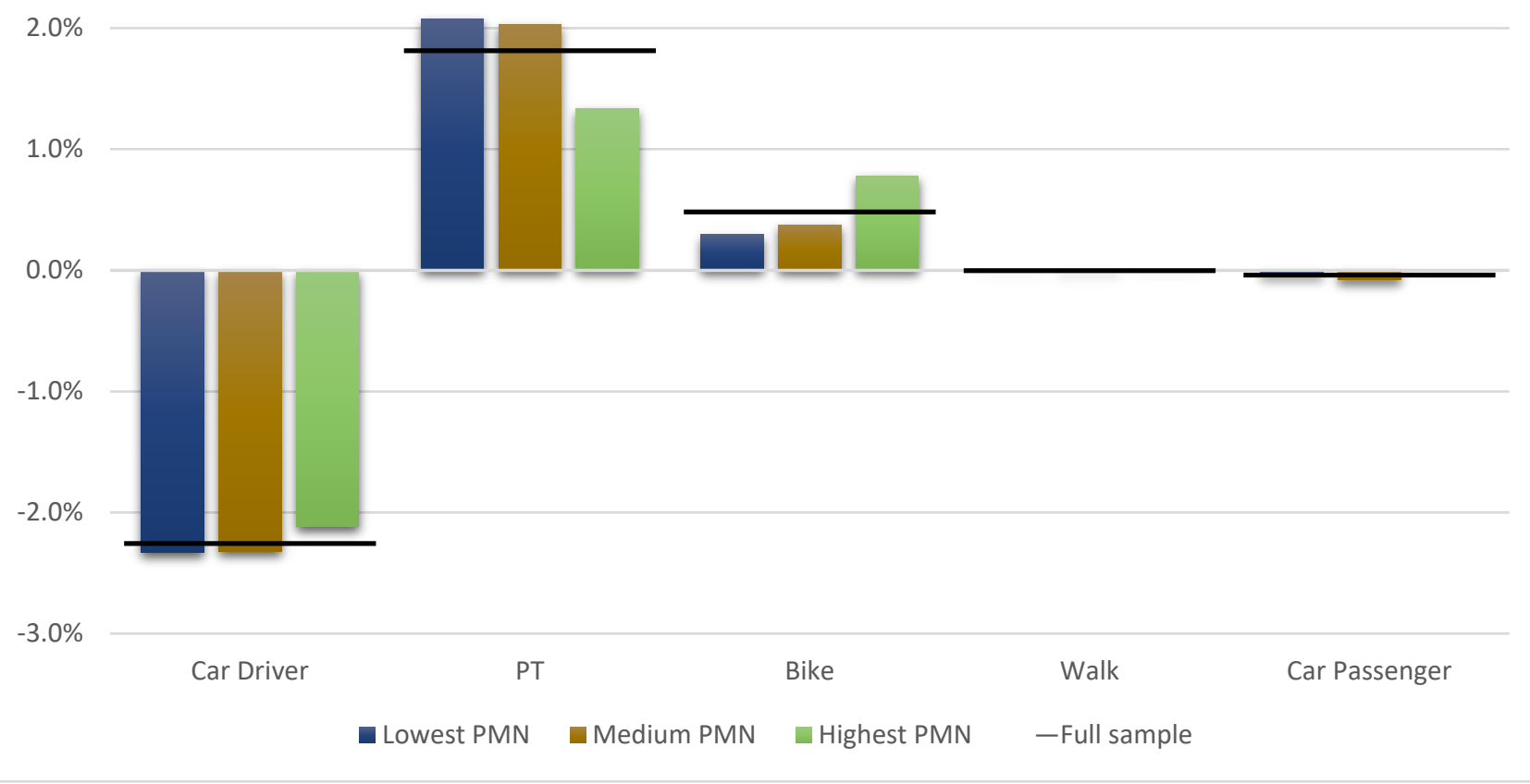

Figure 3: Overview of the model framework for the Integrated Choice and Latent Variable model.

\section{Discussion and Conclusions}

Shifting people's transport choices from private motorised modes to more environmentally friendly modes has been attempted with various hard and soft measures but so far turned out to be a very challenging task. One reason for this has been identified as the need to coordinate constrained activities (e.g. escorting children and commuting to work), which for some people makes it impossible (or at least very unattractive) not to use the private car (e.g., Pooley et al., 2013). In this paper, we looked in more details into the role of activity patterns, related constraints and mobility needs both from an objective and subjective perspective and how these factors influence the mode choice of commuters in Copenhagen. We expected that activity constraints and perceived mobility needs do not only advance car use but also cycling, as citizens in Copenhagen (compared to people in low-cycling cities) perceive the bike as a fast and efficient transport mode (Haustein et al., 2019a).

530 To analyse mode choice decisions for morning commuters in Greater Copenhagen, we estimated an Integrated Choice and Latent Variable (ICLV) model. We explicitly accounted for the complexity of activity patterns, constraints during the morning commute, and the latent variable of Perceived Mobility Necessities (PMN). More specifically, in the choice model we accounted for the entropy of individuals' activities as well as various types of activities (escort, errand, and leisure) during different time-of-day periods (morning, afternoon, and evening). Furthermore, we accounted for the role of constraints through an aggregate measure of constraints in various dimensions (temporal, spatial, social, and compulsory). We found that people with (more) complex activity patterns, a high(er) degree of constraints and a high(er) level of PMN are more likely to select 
individual modes, such as car and bike, while they are less likely to select public transport. This is strengthened by the fact that PMN increased with both the number of activities and the constraints individuals encounter during their commute. These findings confirm our five hypotheses. We believe this is due to the fact that public transport is a relatively rigid (and sometimes unreliable) mode of transportation, and thus would better suit individuals with less complex activity patterns and more flexible schedules as they can adapt to the predefined timetables and stopping locations of public transport (all else equal). Through a policy analysis simulating public transport prioritization, we showed that a higher share of individuals with high PMN shift from car to bike (rather than to public transport) compared to individuals with lower PMN. This result supports our hypothesis that in Copenhagen the bike is regarded as a time-efficient alternative to the car.

While we expect that this finding is transferable to other cities with a distinct cycling culture, in particular cities in the Netherlands (Carstensen and Ebert, 2019; Haustein et al., 2019b; Nello-Deakin and Nikolaeva, 2020), the bike does not play a relevant role as an alternative to the car in low-cycling countries. Thus, in lowcycling countries the relation we found between complex activity patterns, perceived mobility needs and the use of individual modes, is probably restricted to car use. Yet, the result that the bike can have a similar function as the car (at least for short distant trips), may encourage other cities to invest in better conditions for cycling. It is also likely that in southern European cities (e.g., in Greece or Italy), other individual modes, in particular mopeds and motorcycles, can play a similar roles as the bike does in Copenhagen or Amsterdam.

With regard to gender, we found that men are more likely to use car as a driver, while women are more likely to choose all other modes, which resembles earlier findings based on TU-data and might reflect different gender roles determining who is sitting on the driver seat and/or different modal preferences (Haustein et al., 2014). However, this result is in conflict with a recent Canadian study according to which women drive more than men as a result of more mandatory trips for both paid and unpaid work and related time constraints (Shirgaokar and Lanyi-Bennett, 2019). A reason for the conflictive results might be that car ownership in Copenhagen is generally lower than in Canada and having two cars in the household is more often the exception. In addition, cycling is often an alternative to the car, which is - other than in low-cycling countries - more often chosen by women than men (Haustein et al., 2019a).

Structural improvements that ease the handling of a complex everyday life and raise flexibility are, according to our results, likely to decrease car use. Such measures include for example more flexible working and day care times, day care close to the workplace, or escorting services for children, such as "walking school busses" (e.g. Kingham and Ussher, 2007). In Denmark, like in other countries where household tasks are divided more equally among genders, such measures would not only support women, but families in general as well as single parents, who often cannot afford a car, in particular.

Although the findings from our behavioural analysis show that perceived mobility necessities, individuals' activities and their constraints are important factors for modal choices, these factors are usually not included in larger datasets. While this restricts the use for large scale policy analysis today, it may encourage the future inclusions of selected variables, for example in national travel surveys.

\section{Acknowledgement}

The research was conducted during the first author's research exchange at the Institute for Choice, University of South Australia and the first author would like to thank the academic and administrative staff for their hospitality and constructive feedback. The research was partly funded by The Independent Research Fund Denmark, Otto Mønsted Fonden, Cowi Fonden, Reinholdt W. Jorck og hustrus Fond, P. A. Fiskers Fond, 
Hedorfs Fond, IDAs og Berg-Nielsens Studie- og Støttefond. Earlier versions of this research has been presented at the 9th International Symposium on Travel Demand Management (TDM) and the $8^{\text {th }}$ Symposium of the European Association for Research in Transportation (hEART).

\section{Author contributions}

Survey development and data collection was undertaken by Mikkel Thorhauge, Elisabetta Cherchi and Sonja Haustein. The model design, estimation and analysis was performed by Mikkel Thorhauge and Habtamu Tilahun Kassahun, and supervised by Elisabetta Cherchi. The manuscript was drafted by Mikkel Thorhauge and critically revised by Habtamu Tilahun Kassahun, Elisabetta Cherchi and Sonja Haustein. All authors read and approved the final manuscript.

\section{Compliance with ethical standards}

\section{Conflict of interest}

On behalf of all authors, the corresponding author states that there is no conflict of interest.

\section{References}

Ajzen, I., 1991. The theory of planned behavior. Organ. Behav. Hum. Decis. Process. 50, 179-211. https://doi.org/10.1016/0749-5978(91)90020-T

Bamberg, S., 2013. Applying the stage model of self-regulated behavioral change in a car use reduction intervention. J. Environ. Psychol. 33, 68-75. https://doi.org/10.1016/j.jenvp.2012.10.001

Bamberg, S., 2012. Understanding and Promoting Bicycle Use - Insights from Psychological Research, in: Parkin, J. (Ed.), Cycling and Sustainability. Emerald Publishing Group Limited, Bingley, UK, pp. 219246. https://doi.org/10.1108/S2044-9941(2012)0000001011

Bamberg, S., Hunecke, M., Blöbaum, A., 2007. Social context, personal norms and the use of public transportation: Two field studies. J. Environ. Psychol. 27, 190-203. https://doi.org/10.1016/j.jenvp.2007.04.001

Becker, H., Becker, F., Axhausen, K.W., 2019. Impact of vehicle automation and electric propulsion on production costs for mobility services worldwide. https://doi.org/10.3929/ETHZ-B-000341751

Bierlaire, M., 2016. PythonBiogeme : a short introduction, in: Report TRANSP-OR 160706, Series on Biogeme. p. Transport and Mobility Laboratory, School of Archi.

Bonham, J., Wilson, A., 2012. Bicycling and the Life Course: The Start-Stop-Start Experiences of Women Cycling. Int. J. Sustain. Transp. 6, 195-213. https://doi.org/10.1080/15568318.2011.585219

Börjesson, M., Eliasson, J., Hugosson, M.B., Brundell-Freij, K., 2012. The Stockholm congestion charges5 years on. Effects, acceptability and lessons learnt. Transp. Policy 20, 1-12. https://doi.org/10.1016/j.tranpol.2011.11.001 
Bowman, J.L., Ben-Akiva, M.E., 2000. Activity-based disaggregate travel demand model system with activity schedules. Transp. Res. Part A Policy Pract. 35, 1-28. https://doi.org/10.1016/S09658564(99)00043-9

Buehler, R., Pucher, J., Gerike, R., Götschi, T., 2017. Reducing car dependence in the heart of Europe: lessons from Germany, Austria, and Switzerland. Transp. Rev. 37, 4-28. https://doi.org/10.1080/01441647.2016.1177799

Cairns, S., Sloman, L., Newson, C., Anable, J., Kirkbride, A., Goodwin, P., 2008. Smarter Choices: Assessing the Potential to Achieve Traffic Reduction Using 'Soft Measures.' Transp. Rev. 28, 593618. https://doi.org/10.1080/01441640801892504

Carstensen, A.T., Ebert, A.K., 2019. Cycling Cultures in Northern Europe: From 'Golden Age'to 'Renaissance,' in: Cycling and Sustainability. Emerald Group Publishing Limited, pp. 23-58.

Chakrabarti, S., 2017. How can public transit get people out of their cars? An analysis of transit mode choice for commute trips in Los Angeles. Transp. Policy. https://doi.org/10.1016/j.tranpol.2016.11.005

Chandrasekharan, B., Goulias, K.G., 1999. Exploratory longitudinal analysis of solo and joint trip making using the Puget Sound Transportation Panel. Transp. Res. Rec. 77-85.

Cherchi, E., Cirillo, C., 2014. Understanding variability, habit and the effect of long period activity plan in modal choices: a day to day, week to week analysis on panel data. Transportation (Amst). 41, 12451262. https://doi.org/10.1007/s11116-014-9549-y

Cherchi, E., Cirillo, C., Ortúzar, J. de D., 2017. Modelling correlation patterns in mode choice models estimated on multiday travel data. Transp. Res. Part A Policy Pract. 96, 146-153. https://doi.org/10.1016/j.tra.2016.11.021

Christiansen, H., 2018. Beregning af usikkerhed og varians for Transportvaneundersøgelsen, in: Proceedings from the Annual Transport Conference at Aalborg University. https://doi.org/10.11581/dtu:00000034

Christiansen, H., Skovgaard, B.Z., 2015. Documentation of the Danish National Travel Survey. DTU Transport, Data- and Modelcenter.

Christiansen, H., Warnecke, M.-L., 2018. The Danish National Travel Survey - declaration of variables, TU 2006-17, version 1. DTU Transport, Data- and Modelcenter, Technical University of Denmark.

Chu, Y.L., 2003. Empirical Analysis of Commute Stop-Making Behavior, in: Transportation Research Record. https://doi.org/10.3141/1831-12

Cirillo, C., Axhausen, K.W., 2002. Mode choice of complex tours. Arbeitsbericht Verkehrs- und Raumplan. 9-11.

COWI, 2012. Trængselsindikatorer for Hovedstadsregionen.

Currie, G., Delbosc, A., 2011. Exploring the trip chaining behaviour of public transport users in Melbourne. Transp. Policy. https://doi.org/10.1016/j.tranpol.2010.08.003

Donald, I.J., Cooper, S.R., Conchie, S.M., 2014. An extended theory of planned behaviour model of the psychological factors affecting commuters' transport mode use. J. Environ. Psychol. 40, 39-48. https://doi.org/10.1016/j.jenvp.2014.03.003

Dong, X., Ben-Akiva, M.E., Bowman, J.L., Walker, J.L., 2006. Moving from trip-based to activity-based measures of accessibility. Transp. Res. Part A Policy Pract. https://doi.org/10.1016/j.tra.2005.05.002 
Fosgerau, M., Hjorth, K., Lyk-Jensen, S.V., 2007. The Danish Value of Time Study. Danish Transport Research Institute.

Hägerstrand, T., 1970. How about people in regional science? Pap. Reg. Sci. Assoc. 24, 7-21.

Haustein, S., Hunecke, M., 2007. Reduced use of environmentally friendly modes of transportation caused by perceived mobility necessities: An extension of the theory of planned behavior. J. Appl. Soc. Psychol. 37, 1856-1883. https://doi.org/10.1111/j.1559-1816.2007.00241.x

Haustein, S., Koglin, T., Nielsen, T.A.S., Svensson, Å., 2019a. A comparison of cycling cultures in Stockholm and Copenhagen. Int. J. Sustain. Transp. 1-14. https://doi.org/10.1080/15568318.2018.1547463

Haustein, S., Kroesen, M., Mulalic, I., 2019b. Cycling culture and socialisation: modelling the effect of immigrant origin on cycling in Denmark and the Netherlands. Transportation (Amst). https://doi.org/10.1007/s11116-019-09978-6

Hendrickson, C., Planke, E., 1984. The flexibility of departure times for work trips. Transp. Res. Part A Policy Pract. 18, 25-36.

Hess, S., Polak, J.W., Daly, A., Hyman, G., 2007. Flexible substitution patterns in models of mode and time of day choice: new evidence from the UK and the Netherlands. Transportation (Amst). 34, $213-238$.

Hidalgo, D., Pereira, L., Estupiñán, N., Jiménez, P.L., 2013. TransMilenio BRT system in Bogota, high performance and positive impact - Main results of an ex-post evaluation. Res. Transp. Econ. 39, 133138. https://doi.org/10.1016/j.retrec.2012.06.005

Kingham, S., Ussher, S., 2007. An assessment of the benefits of the walking school bus in Christchurch, New Zealand. Transp. Res. Part A Policy Pract. 41, 502-510. https://doi.org/10.1016/j.tra.2006.11.008

Lanzini, P., Khan, S.A., 2017. Shedding light on the psychological and behavioral determinants of travel mode choice: A meta-analysis. Transp. Res. Part F Traffic Psychol. Behav. 48, 13-27. https://doi.org/10.1016/j.trf.2017.04.020

Likert, R., 1932. A technique for the measurement of attitudes. Arch. Psychol. 22, 5-55.

McBride, E.C., Davis, A.W., Goulias, K.G., 2019. Fragmentation in Daily Schedule of Activities using Activity Sequences. Transp. Res. Rec. J. Transp. Res. Board 2673, 844-854. https://doi.org/10.1177/0361198119837501

McBride, E.C., Davis, Adam Wilkinson, Goulias, K.G., 2020. Sequence Analysis of Place-Travel Fragmentation in California, in: Goulias, K.G., Davis, Adam W. (Eds.), Mapping the Travel Behabior Genome. Elsevier, pp. 371-398. https://doi.org/https://doi.org/10.1016/C2018-0-02132-5

McGuckin, N., Zmud, J., Nakamoto, Y., 2005. Trip-chaining trends in the United States: Understanding travel behavior for policy making, in: Transportation Research Record. https://doi.org/10.3141/1917-22

Modelcenter, 2019. Transportøkonomiske Enhedspriser - til brug for samfundsøkonomiske analyser v1.91.

Möser, G., Bamberg, S., 2008. The effectiveness of soft transport policy measures: A critical assessment and meta-analysis of empirical evidence. J. Environ. Psychol. 28, 10-26. https://doi.org/10.1016/j.jenvp.2007.09.001

Municipalities, T.F. of, 2008. Congestion Charging in the Greater Copenhagen Area. Forum of Municipalities in conjunction with consultants from Tetraplan, COWI, Rambøll Nyvig, Copenhagen Economics, A2 and Key Research. 
Nello-Deakin, S., Nikolaeva, A., 2020. The human infrastructure of a cycling city: Amsterdam through the eyes of international newcomers. Urban Geogr. 1-23. https://doi.org/10.1080/02723638.2019.1709757

Ortúzar, J. de D., Willumsen, L.G., 2011. Modelling Transport, Modelling Transport. Wiley. https://doi.org/10.1002/9781119993308

Pooley, C.G., Horton, D., Scheldeman, G., Mullen, C., Jones, T., Tight, M., Jopson, A., Chisholm, A., 2013. Policies for promoting walking and cycling in England: A view from the street. Transp. Policy 27, 6672. https://doi.org/10.1016/j.tranpol.2013.01.003

Pucher, J., Buehler, R., 2012. City Cycling. MIT Press. https://doi.org/http://dx.doi.org/10.1080/09654313.2013.798111

Rich, J., Hansen, C.O., 2016. The Danish national passenger model - Model specification and results. Eur. J. Transp. Infrastruct. Res. 16, 573-599. https://doi.org/10.18757/ejtir.2016.16.4.3159

Scheiner, J., 2014. The gendered complexity of daily life: Effects of life-course events on changes in activity entropy and tour complexity over time. Travel Behav. Soc. 1, 91-105. https://doi.org/10.1016/j.tbs.2014.04.001

Shirgaokar, M., Lanyi-Bennett, K., 2019. I'll have to drive there: How daily time constraints impact women's car use differently than men's. Transportation (Amst). https://doi.org/10.1007/s11116-0189969-1

Skov-Petersen, H., Jacobsen, J.B., Vedel, S.E., Thomas Alexander, S.N., Rask, S., 2017. Effects of upgrading to cycle highways - An analysis of demand induction, use patterns and satisfaction before and after. J. Transp. Geogr. 64, 203-210. https://doi.org/10.1016/j.jtrangeo.2017.09.011

Thorhauge, M., 2015. Departure time choice: Modelling individual preferences, intention and constraints. Department of Transportation and Logistics, Technical University of Denmark, Kgs. Lyngby, Denmark.

Thorhauge, M., Cherchi, E., Rich, J., 2016. How flexible is flexible? Accounting for the effect of rescheduling possibilities in choice of departure time for work trips. Transp. Res. Part A Policy Pract. 86, 177-193. https://doi.org/10.1016/j.tra.2016.02.006

Thorhauge, M., Cherchi, E., Walker, J.L., Rich, J., 2019. The role of intention as mediator between latent effects and behavior: application of a hybrid choice model to study departure time choices. Transportation (Amst). 46, 1421-1445. https://doi.org/10.1007/s11116-017-9839-2

Thorhauge, M., Vuk, G., Kaplan, S., 2012. A survey of joint activities and travel of household members in the Greater Copenhagen Metropolitan Region. Sel. Proc. from Annu. Transp. Conf. Aalborg Univ.

Vande Walle, S., Steenberghen, T., 2006. Space and time related determinants of public transport use in trip chains. Transp. Res. Part A Policy Pract. https://doi.org/10.1016/j.tra.2005.05.001

Vejdirektoratet, 2016. Trafikal analyse af hovedstadsområdet (Rapport 563).

Walker, J., 2001. Extended Discrete Choice Models: Integrated Framework, Flexible Error Structures, and Latent Variables. Environ. Eng. Massachusetts Institute of Technology. https://doi.org/http://transpor.epfl.ch/courses/dca2012/WalkerPhD.pdf

Walker, J., Ben-Akiva, M., 2002. Generalized random utility model. Math. Soc. Sci. 43, 303-343. https://doi.org/10.1016/S0165-4896(02)00023-9

Wan, X., Candidate, P.D., 2011. Private Car Use and Its Interdependence on Activity Pattern in China. 
Witlox, F., Tindemans, H., 2004. Evaluating bicycle-car transport mode competitiveness in an urban environment. An activity-based approach. World Transp. Policy Pract. 10, 32-42.

Xianyu, J., 2013. An Exploration of the Interdependencies between Trip Chaining Behavior and Travel Mode Choice. Procedia - Soc. Behav. Sci. 96, 1967-1975. https://doi.org/10.1016/j.sbspro.2013.08.222

Yamamoto, T., Kitamura, R., 1999. An analysis of time allocation to in-home and out-of-home discretionary activities across working days and non-working days. Transportation (Amst). 26, 211-230.

Yáñez, M.F., Raveau, S., Ortúzar, J. de D., 2010. Inclusion of latent variables in Mixed Logit models: Modelling and forecasting. Transp. Res. Part A Policy Pract. 44, 744-753. https://doi.org/10.1016/j.tra.2010.07.007

Yarlagadda, A.K., Srinivasan, S., 2008. Modeling children's school travel mode and parental escort decisions. Transportation (Amst). 35, 201-218. https://doi.org/10.1007/s11116-007-9144-6

Ye, X., Pendyala, R.M., Gottardi, G., 2007. An exploration of the relationship between mode choice and complexity of trip chaining patterns. Transp. Res. Part B Methodol. 41, 96-113. https://doi.org/10.1016/j.trb.2006.03.004 


\section{Appendix with Tables}

Table 3a: Socio-demographics

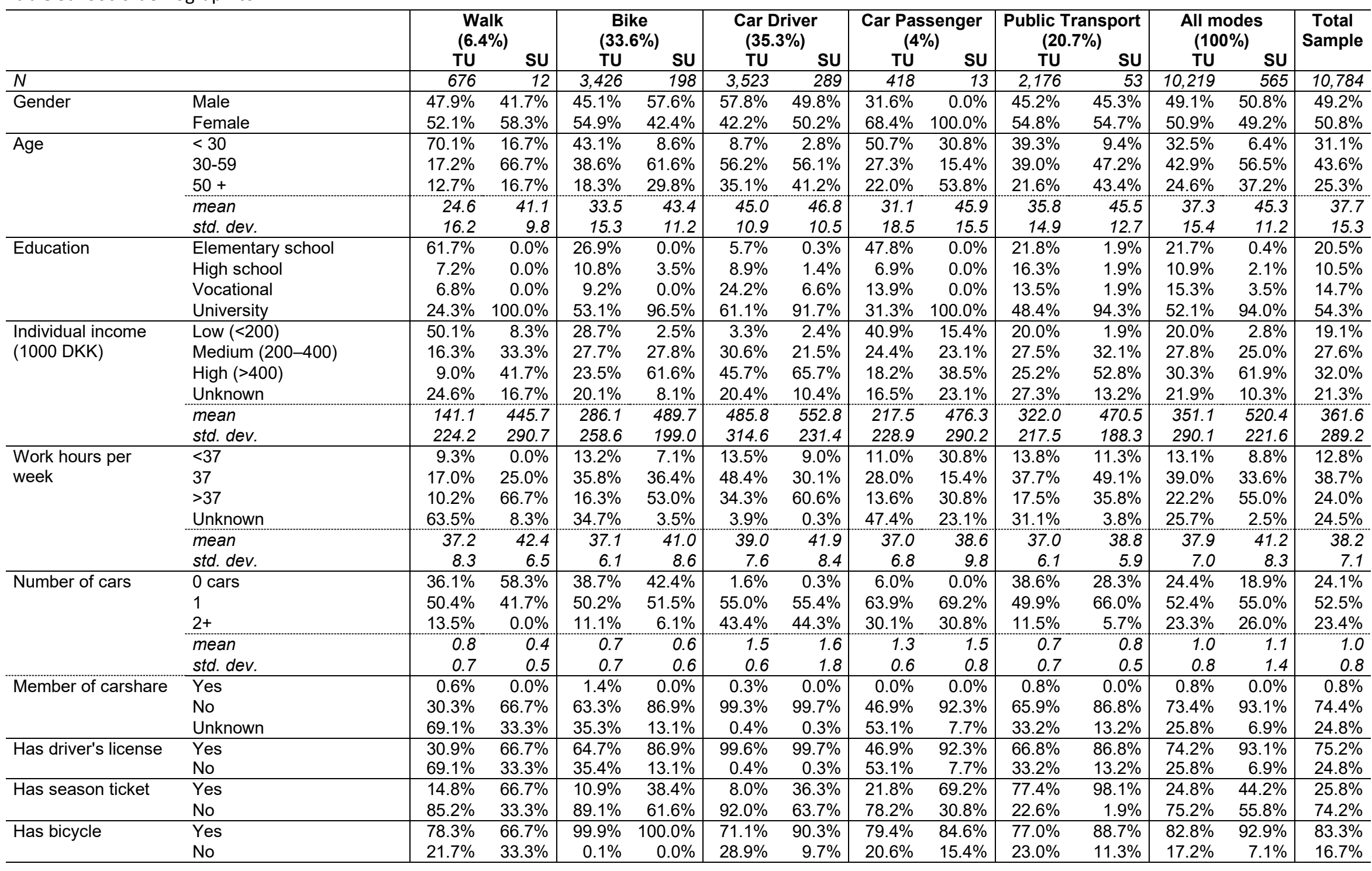


Table 3b: Travel characteristics

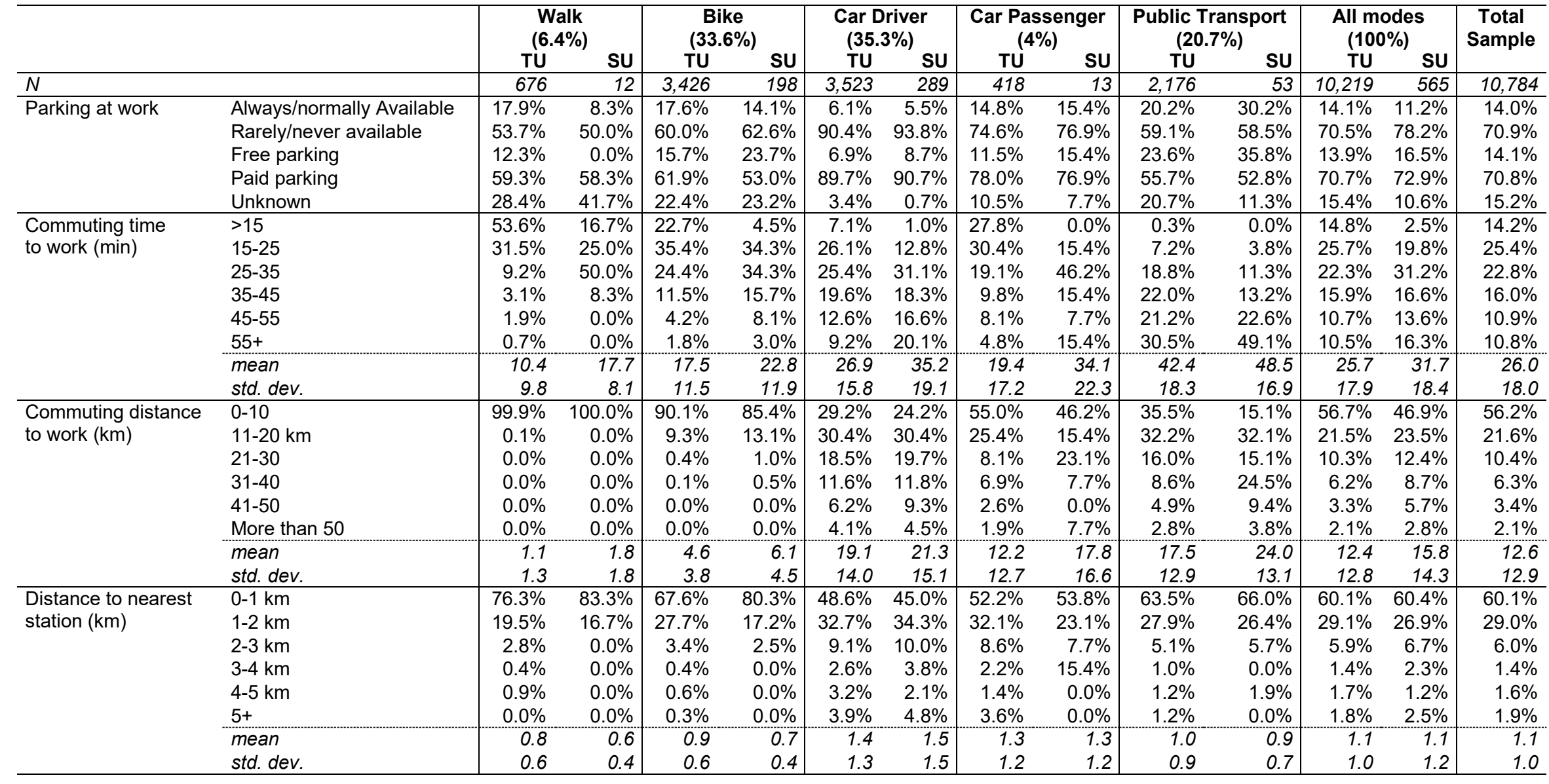


Table 3c: Activity patterns

\begin{tabular}{|c|c|c|c|c|c|c|c|c|c|c|c|c|c|c|}
\hline & & \multicolumn{2}{|c|}{$\begin{array}{c}\text { Walk } \\
(6.4 \%)\end{array}$} & \multicolumn{2}{|c|}{$\begin{array}{c}\text { Bike } \\
(33.6 \%)\end{array}$} & \multicolumn{2}{|c|}{$\begin{array}{c}\text { Car Driver } \\
(35.3 \%)\end{array}$} & \multicolumn{2}{|c|}{$\begin{array}{c}\text { Car Passenger } \\
(4 \%)\end{array}$} & \multicolumn{2}{|c|}{$\begin{array}{c}\text { Public Transport } \\
\text { (20.7\%) }\end{array}$} & \multicolumn{2}{|c|}{$\begin{array}{l}\text { All modes } \\
(100 \%)\end{array}$} & \multirow[t]{2}{*}{$\begin{array}{c}\text { Total } \\
\text { Sample }\end{array}$} \\
\hline & & TU & SU & TU & SU & TU & sU & TU & SU & TU & SU & TU & SU & \\
\hline \multicolumn{2}{|l|}{$N$} & 676 & 12 & 3,426 & 198 & 3,523 & 289 & 418 & 13 & 2,176 & 53 & 10,219 & 565 & 10,784 \\
\hline \multirow{7}{*}{$\begin{array}{l}\text { Number of } \\
\text { (out-of-home) } \\
\text { activities }\end{array}$} & $1-2$ act & $34.0 \%$ & $50.0 \%$ & $29.9 \%$ & $42.4 \%$ & $31.7 \%$ & $38.8 \%$ & $38.8 \%$ & $30.8 \%$ & $47.5 \%$ & $47.2 \%$ & $34.9 \%$ & $40.9 \%$ & $35.2 \%$ \\
\hline & $3-4$ act & $42.9 \%$ & $41.7 \%$ & $44.0 \%$ & $37.9 \%$ & $40.3 \%$ & $46.0 \%$ & $41.6 \%$ & $38.5 \%$ & $38.2 \%$ & $45.3 \%$ & $41.4 \%$ & $42.8 \%$ & $41.4 \%$ \\
\hline & $5-6$ act & $17.8 \%$ & $8.3 \%$ & $19.9 \%$ & $14.6 \%$ & $19.0 \%$ & $12.8 \%$ & $15.3 \%$ & $15.4 \%$ & $11.9 \%$ & $5.7 \%$ & $17.6 \%$ & $12.7 \%$ & $17.3 \%$ \\
\hline & $7-8$ act & $3.8 \%$ & $0.0 \%$ & $4.4 \%$ & $4.5 \%$ & $5.9 \%$ & $2.4 \%$ & $3.3 \%$ & $15.4 \%$ & $2.0 \%$ & $1.9 \%$ & $4.3 \%$ & $3.4 \%$ & $4.3 \%$ \\
\hline & $9+$ act & $1.5 \%$ & $0.0 \%$ & $1.8 \%$ & $0.5 \%$ & $3.0 \%$ & $0.0 \%$ & $1.0 \%$ & $0.0 \%$ & $0.4 \%$ & $0.0 \%$ & $1.8 \%$ & $0.2 \%$ & $1.8 \%$ \\
\hline & mean & 3.7 & 2.8 & 3.8 & 3.3 & 3.8 & 3.2 & 3.4 & 3.9 & 3.1 & 2.9 & 3.7 & 3.2 & 3.6 \\
\hline & std. dev. & 1.7 & 1.0 & 2.6 & 1.6 & 1.9 & 1.4 & 1.6 & 1.9 & 1.4 & 1.2 & 2.1 & 1.4 & 2.1 \\
\hline \multirow{2}{*}{$\begin{array}{l}\text { Has escort activity } \\
\text { - Home-Work (HW) }\end{array}$} & Yes & $1.5 \%$ & $16.7 \%$ & $5.6 \%$ & $13.6 \%$ & $12.6 \%$ & $14.5 \%$ & $5.7 \%$ & $7.7 \%$ & $4.5 \%$ & $13.2 \%$ & $7.5 \%$ & $14.0 \%$ & $7.9 \%$ \\
\hline & No & $98.5 \%$ & $83.3 \%$ & $94.4 \%$ & $86.4 \%$ & $87.4 \%$ & $85.5 \%$ & $94.3 \%$ & $92.3 \%$ & $95.5 \%$ & $86.8 \%$ & $92.5 \%$ & $86.0 \%$ & $92.1 \%$ \\
\hline \multirow{2}{*}{$\begin{array}{l}\text { Has errand activity } \\
\text { - Home-Work (HW) }\end{array}$} & Yes & $0.1 \%$ & $8.3 \%$ & $0.9 \%$ & $1.0 \%$ & $1.3 \%$ & $2.1 \%$ & $2.2 \%$ & $0.0 \%$ & $0.7 \%$ & $0.0 \%$ & $1.0 \%$ & $1.6 \%$ & $1.0 \%$ \\
\hline & No & $99.9 \%$ & $91.7 \%$ & $99.1 \%$ & $99.0 \%$ & $98.7 \%$ & $97.9 \%$ & $97.8 \%$ & $100.0 \%$ & $99.3 \%$ & $100.0 \%$ & $99.0 \%$ & $98.4 \%$ & $99.0 \%$ \\
\hline \multirow{2}{*}{$\begin{array}{l}\text { Has Leisure activity } \\
\text { - Home-Work (HW) }\end{array}$} & Yes & $0.4 \%$ & $0.0 \%$ & $0.4 \%$ & $1.0 \%$ & $0.9 \%$ & $1.0 \%$ & $0.7 \%$ & $0.0 \%$ & $0.5 \%$ & $0.0 \%$ & $0.6 \%$ & $0.9 \%$ & $0.6 \%$ \\
\hline & No & $99.6 \%$ & $100.0 \%$ & $99.6 \%$ & $99.0 \%$ & $99.1 \%$ & $99.0 \%$ & $99.3 \%$ & $100.0 \%$ & $99.5 \%$ & $100.0 \%$ & $99.4 \%$ & $99.1 \%$ & $99.4 \%$ \\
\hline \multirow{2}{*}{$\begin{array}{l}\text { Has escort activity } \\
\text { - Work-Home (WH) }\end{array}$} & Yes & $1.9 \%$ & $8.3 \%$ & $6.0 \%$ & $8.6 \%$ & $12.5 \%$ & $17.0 \%$ & $4.8 \%$ & $23.1 \%$ & $4.2 \%$ & $9.4 \%$ & $7.5 \%$ & $13.3 \%$ & $7.8 \%$ \\
\hline & No & $98.1 \%$ & $91.7 \%$ & $94.0 \%$ & $91.4 \%$ & $87.5 \%$ & $83.0 \%$ & $95.2 \%$ & $76.9 \%$ & $95.8 \%$ & $90.6 \%$ & $92.5 \%$ & $86.7 \%$ & $92.2 \%$ \\
\hline \multirow{2}{*}{$\begin{array}{l}\text { Has errand activity } \\
\text { - Work-Home (WH) }\end{array}$} & Yes & $9.0 \%$ & $0.0 \%$ & $14.2 \%$ & $8.1 \%$ & $17.7 \%$ & $14.2 \%$ & $14.4 \%$ & $15.4 \%$ & $11.4 \%$ & $17.0 \%$ & $14.5 \%$ & $12.0 \%$ & $14.3 \%$ \\
\hline & No & $91.0 \%$ & $100.0 \%$ & $85.8 \%$ & $91.9 \%$ & $82.3 \%$ & $85.8 \%$ & $85.6 \%$ & $84.6 \%$ & $88.6 \%$ & $83.0 \%$ & $85.5 \%$ & $88.0 \%$ & $85.7 \%$ \\
\hline \multirow{2}{*}{$\begin{array}{l}\text { Has Leisure activity } \\
\text { - Work-Home (WH) }\end{array}$} & Yes & $16.3 \%$ & $8.3 \%$ & $16.7 \%$ & $11.6 \%$ & $10.1 \%$ & $10.4 \%$ & $15.8 \%$ & $23.1 \%$ & $11.2 \%$ & $5.7 \%$ & $13.2 \%$ & $10.6 \%$ & $13.1 \%$ \\
\hline & No & $83.7 \%$ & $91.7 \%$ & $83.3 \%$ & $88.4 \%$ & $89.9 \%$ & $89.6 \%$ & $84.2 \%$ & $76.9 \%$ & $88.8 \%$ & $94.3 \%$ & $86.8 \%$ & $89.4 \%$ & $86.9 \%$ \\
\hline \multirow{2}{*}{$\begin{array}{l}\text { Has escort activity } \\
\text { - After Work (AW) }\end{array}$} & Yes & $3.1 \%$ & $0.0 \%$ & $4.8 \%$ & $3.5 \%$ & $7.9 \%$ & $2.4 \%$ & $4.1 \%$ & $0.0 \%$ & $3.5 \%$ & $1.9 \%$ & $5.5 \%$ & $2.7 \%$ & $5.3 \%$ \\
\hline & No & $96.9 \%$ & $100.0 \%$ & $95.2 \%$ & $96.5 \%$ & $92.1 \%$ & $97.6 \%$ & $95.9 \%$ & $100.0 \%$ & $96.5 \%$ & $98.1 \%$ & $94.5 \%$ & $97.3 \%$ & $94.7 \%$ \\
\hline \multirow{2}{*}{$\begin{array}{l}\text { Has errand activity } \\
\text { - After Work (AW) }\end{array}$} & Yes & $11.1 \%$ & $0.0 \%$ & $13.3 \%$ & $13.6 \%$ & $11.6 \%$ & $3.5 \%$ & $8.4 \%$ & $0.0 \%$ & $8.4 \%$ & $3.8 \%$ & $11.3 \%$ & $6.9 \%$ & $11.1 \%$ \\
\hline & No & $88.9 \%$ & $100.0 \%$ & $86.7 \%$ & $86.4 \%$ & $88.4 \%$ & $96.5 \%$ & $91.6 \%$ & $100.0 \%$ & $91.6 \%$ & $96.2 \%$ & $88.7 \%$ & $93.1 \%$ & $88.9 \%$ \\
\hline \multirow{2}{*}{$\begin{array}{l}\text { Has Leisure activity } \\
\text { - After Work (AW) }\end{array}$} & Yes & $33.3 \%$ & $8.3 \%$ & $28.3 \%$ & $14.1 \%$ & $20.3 \%$ & $10.7 \%$ & $23.9 \%$ & $30.8 \%$ & $18.4 \%$ & $9.4 \%$ & $23.6 \%$ & $12.2 \%$ & $23.0 \%$ \\
\hline & No & $66.7 \%$ & $91.7 \%$ & $71.7 \%$ & $85.9 \%$ & $79.7 \%$ & $89.3 \%$ & $76.1 \%$ & $69.2 \%$ & $81.6 \%$ & $90.6 \%$ & $76.4 \%$ & $87.8 \%$ & $77.0 \%$ \\
\hline
\end{tabular}

